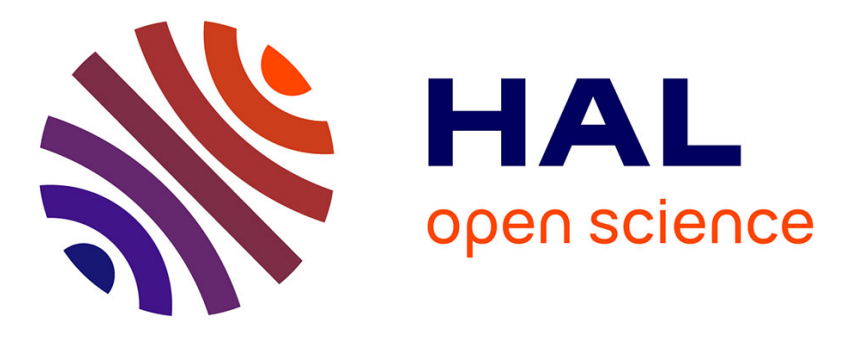

\title{
The Membrane-Bound Mucins: How Large O-Glycoproteins Play Key Roles in Epithelial Cancers and Hold Promise as Biological Tools for Gene-Based and Immunotherapies
}

Nicolas Jonckheere, Isabelle Van Seuningen

\section{To cite this version:}

Nicolas Jonckheere, Isabelle Van Seuningen. The Membrane-Bound Mucins: How Large OGlycoproteins Play Key Roles in Epithelial Cancers and Hold Promise as Biological Tools for Gene-Based and Immunotherapies. Critical Review in Oncogenesis, 2008, 14 (2-3), pp.177-196. 10.1615/CritRevOncog.v14.i2-3.30 . hal-02905788

\section{HAL Id: hal-02905788 \\ https://hal.science/hal-02905788}

Submitted on 29 Sep 2020

HAL is a multi-disciplinary open access archive for the deposit and dissemination of scientific research documents, whether they are published or not. The documents may come from teaching and research institutions in France or abroad, or from public or private research centers.
L'archive ouverte pluridisciplinaire $\mathbf{H A L}$, est destinée au dépôt et à la diffusion de documents scientifiques de niveau recherche, publiés ou non, émanant des établissements d'enseignement et de recherche français ou étrangers, des laboratoires publics ou privés. 


\title{
The Membrane-Bound Mucins: How Large O-Glycoproteins Play Key Roles in Epithelial Cancers and Hold Promise as Biological Tools for Gene and Immunotherapies
}

\section{Nicolas Jonckheere \& Isabelle Van Seuningen}

Inserm, U837, Centre de Recherche Jean-Pierre Aubert, Place de Verdun, Lille, F-59045 France

Address all correspondence to Dr. Isabelle Van Seuningen, Inserm U837, Team 5 "Mucins, epithelial differentiation and carcinogenesis," Centre de Recherche Jean-Pierre Aubert, Place de Verdun, 59045 Lille cedex, France; isabelle.vanseuningen@inserm.fr

\begin{abstract}
Membrane-bound mucins belong to an ever-increasing family of $O$-glycoproteins that share a structure conserved throughout evolution. Typically, membrane-bound mucins contain a long extracellular domain, a hydrophobic transmembrane domain, and a short cytoplasmic tail. They are modular proteins and have a structural organization containing Pro/ $\mathrm{Thr} /$ Ser-rich O-glycosylated domains and EGF-like domains. The biological roles of mucins arise from t $\equiv$ tructures. MUC1 and MUC4 modulate biological properties of the cell, alter its behavior and modulate cell signaling pathways associated with tumorigenesis. Altered expression and post-translational modifications confer an important role to MUC1 and MUC4 in tumor progression, metastasis, and cancer cell chimioresistance. Moreover, increasing knowledge about their animal counterparts has made possible a greater understanding of their pathophysiological role in vivo. Most biological functions attributed to MUC4 are based on the structural homology with its rat homologue. From these results, the development of new biological tools targeting mucins has been increasing and the recent attention given to these complex molecules may bring hope for improved cancer treatments in the future. This review discusses the structure/function of MUC1 and MUC4 membrane-bound mucins in relation to cancer cell behavior and cell signaling pathways associated with tumorigenesis, as well as their potential as biological tools for gene therapy and immunotherapy approaches.
\end{abstract}

KEY WORDS: mucin, cancer, MUC1, MUC4, proliferation, tumor progression, therapeutic target, cell signaling, chimioresistance 


\section{INTRODUCTION TO MEMBRANE-BOUND MUCINS}

Mucins are a heterogeneous family of large $O$-glycoproteins composed of a long peptidic chain called apomucin on which are linked hundreds of oligosaccharidic chains. On the basis of biochemical studies, mucins were initially defined as high molecular weight (MW) molecules secreted by epithelia, which are able to form viscoelastic gels and are responsible for the rheological properties of mucus. They were additionally characterized by a high content in serine (Ser), threonine (Thr), and proline (Pro) residues.

The advent of molecular biology in the 1990s enabled the identification of high MW $O$-glycoproteins with structural characteristics of mucins that contained a transmembrane (TM) domain. Today, the family of membrane-bound mucins includes MUC1, MUC3A/B, MUC4, MUC12, MUC13, MUC15, MUC16, MUC17, MUC20, and MUC21. ${ }^{1}$ Among them, MUC1 and MUC4 are best characterized. Overexpression of membrane-bound mucins in numerous cancers is often associated with a poor prognosis. Because of their structure and cellular localization, they play biological roles in extracellular cell-cell, cell-matrix interactions, and in cell signaling, and they modulate biological properties of cancer cells. Thus, membrane-bound mucins offer exciting opportunities and stay under intense investigation as both potential biomarkers and therapeutic targets in epithelial cancers.

This review focuses on the structure/function of MUC1 and MUC4 membranebound mucins in relation to cancer cell behavior and cell signaling pathways associated with tumorigenesis. In addition, we discuss the potential of membrane-bound mucins as biological tools for both gene- and immunobased therapeutical approaches.

\section{MUC1}

\section{II.A. Structure of the MUC1 Gene}

MUC1 was the first mucin gene characterized in $1991 .^{2-4}$ MUC1 is localized on chromosome 1 at q21-q24, contains 7 exons, and has a 4- to 7-kb size because of a variable number of tandem repeat (VNTR) polymorphisms varying in size from 400 to 2400 residues. ${ }^{5}$ MUC1 is structurally organized in domains: exon 1 encodes the signal peptide, and exon 2 encodes the central domain. This central domain comprises a sequence repeated in tandem with a unit of 20 amino acids (aa). Variations in the number of tandem repeats and sequences of the individual TRs are observed and could have potential functional consequences. ${ }^{6}$ Therefore, it was shown that MUC1 small allele distribution is increased in gastric carcinoma patient populations. ${ }^{7}$ Exons 6 and 7 encode the TM domain and cytoplasmic tail, respectively. (For reviews on the structure of MUC1 gene, see Ref. 8.)

\section{II.B. Structure of the MUC1 Protein}

The MUC1 mucin is also known as polymorphic epithelial mucin (PEM), episialin, DUPAN-2, DF3, human milk fat globule (HMFG), epithelial membrane antigen 
(EMA), and CD227. ${ }^{9}$ This mucin lacks both the domain responsible for polymerization and EGF domains usually found in the other membrane-bound mucins (Fig. 1). The MUC1 apomucin contains an O-glycosylated repeated central domain and a 72aa cytoplasmic tail. MUC1 also contains five potential N-glycosylation sites located in the SEA domain following the tandem repeat (TR). ${ }^{10}$ The MUC1 SEA module is a self-cleavage domain. ${ }^{11}$ It was recently shown that extracellular and TM subunits of MUC1 are cleaved in the rough endoplasmic reticulum (RER) at the FRPG/SVVV site localized between the SEA domain and the TM unit. ${ }^{12}$ The SEA module occurs in many membrane-associated proteins that are released from the cell surface and has been implicated in both cleavage events and association of the subunits, which are noncovalently linked. MUC1 resides at the apical side of the cell because of a site contained within the extracellular domain and a CQC site located at the junction between the cytoplasmic and TM domains (Fig. 2). ${ }^{13}$

Diverse glycosylation events at the MUC1 extracellular domain provide tissuespecific interactions with the host environment. Changes in the carbohydrate epitopes carried by MUC1 have been detected in many carcinomas, such as those of the colon

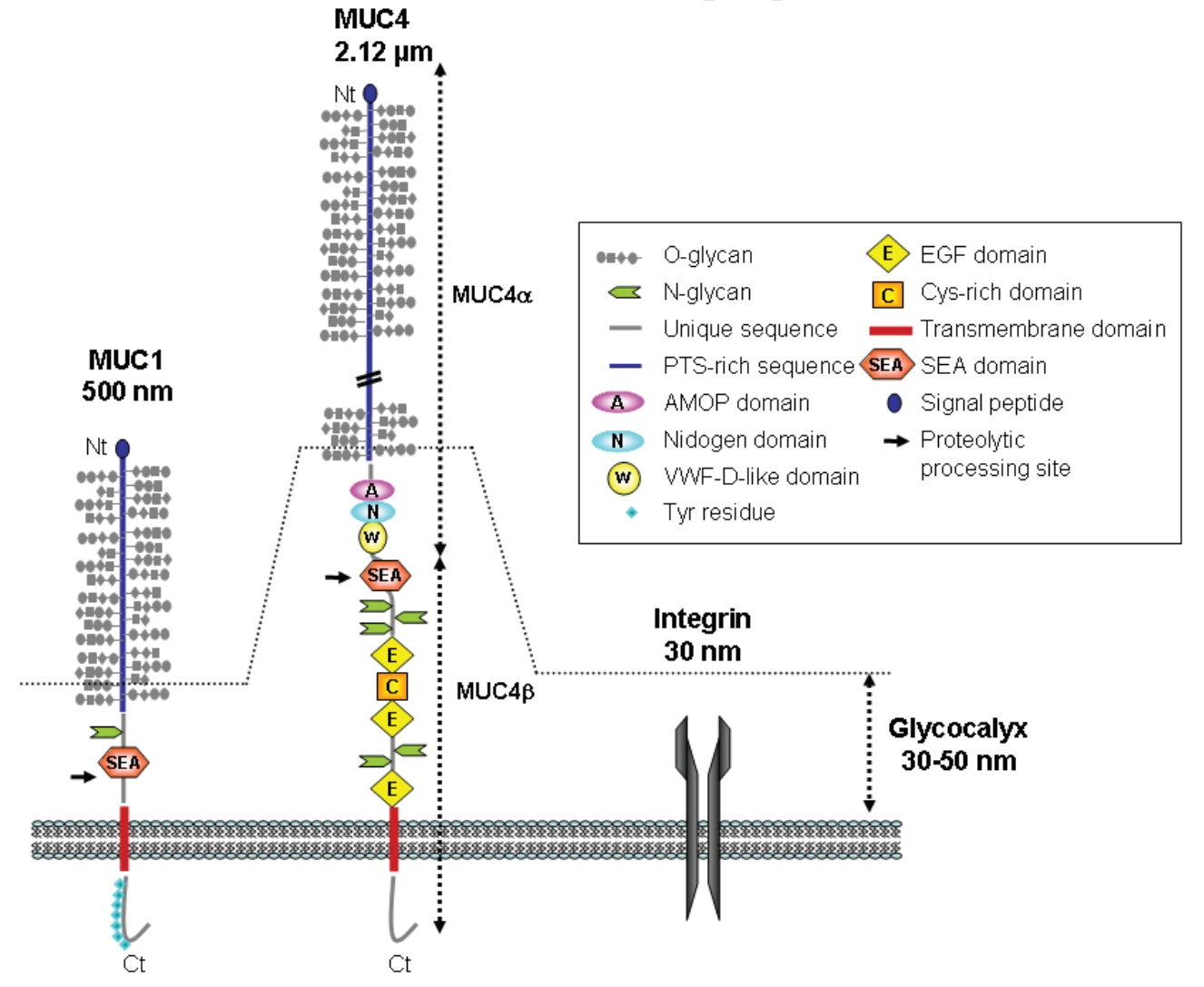

FIGURE 1. Conserved modular organization of MUC1 and MUC4 membrane-bound mucins. 


\section{N. JoncKheERE \& I. VAN SEUningen}

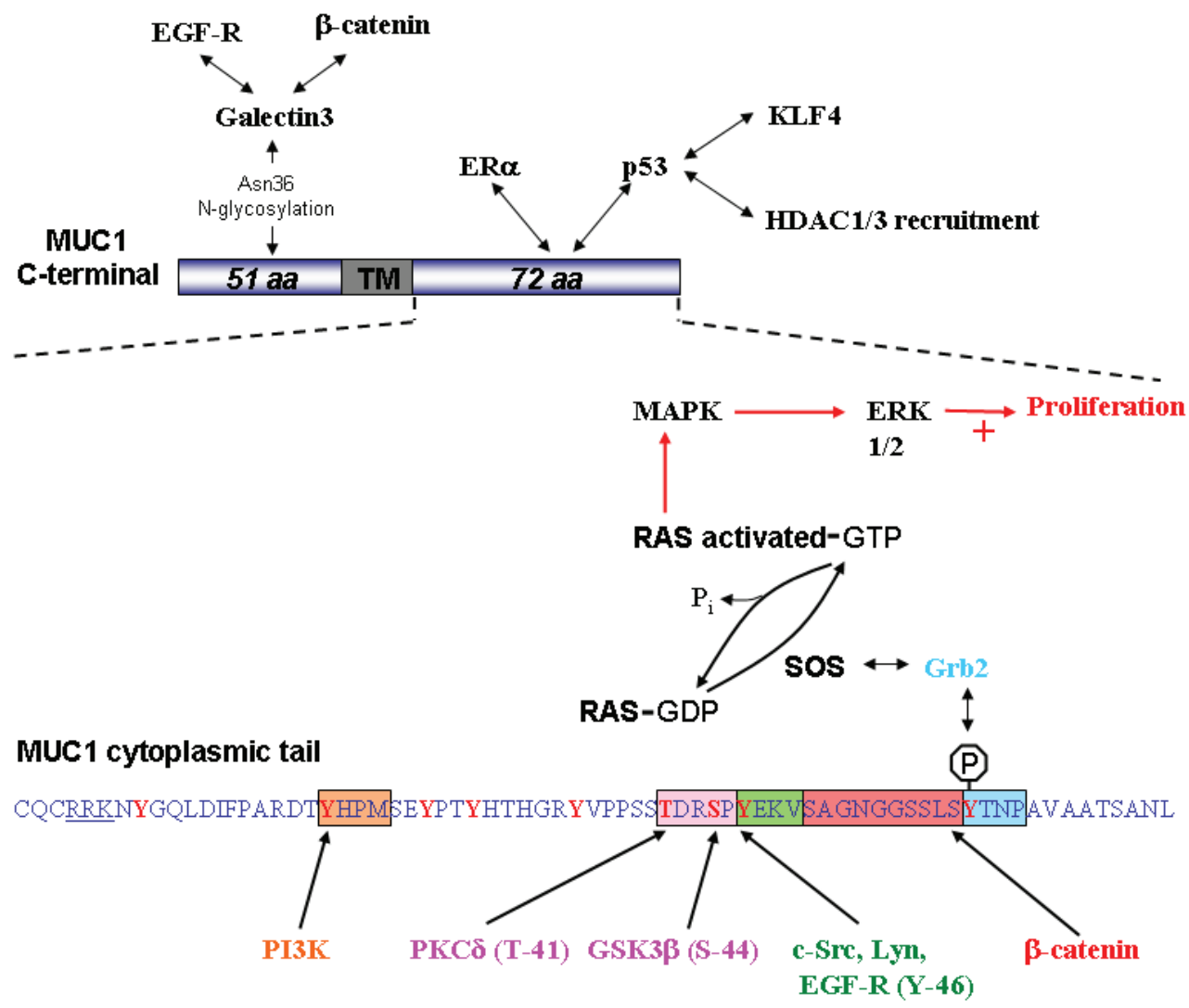

FIGURE 2. MUC1 and cell signaling. The MUC1 C-terminal subunit and cytoplasmic tail allow the interaction of MUC1 with a wide array of signaling pathways in tumor cells.

or breast. In malignant epithelial cells, the MUC1 glycosylation pattern and distribution on the polypeptide are both altered. These alterations are associated with metastatic progression and generation of immunogenic epitopes. ${ }^{14}$

$M U C 1$ can also undergo alternative splicing, which leads to splice variants such as $M U C 1 / S E C$ or $M U C 1 / Y$. MUC1/SEC results from an alternative splicing event occurring in the 3 '-end of the TR array and consequently does not possess the TM sequence and cytoplasmic tail. ${ }^{15} \mathrm{MUC1} / \mathrm{Y}$ is an alternative splice variant with a $1.2-\mathrm{kb}$ full length cDNA resulting from deletion of the mucin-like central domain. ${ }^{16} \mathrm{MUC} 1 / \mathrm{Y}$ appears to act as a membrane receptor, which undergoes Tyr and Ser phosphorylation and activates cell signaling via Grb2. ${ }^{17}$ Other splice variants have been described, but their real function is currently unknown.

\section{II.C. MUC1 and Cell Signaling}

Several laboratories have shown that MUC1 is involved in cell signaling. ${ }^{18,19}$ The cytoplasmic tail contains 7 Tyr residues, an SH2 interaction domain, and several 
kinase phosphorylation sites (Fig. 2). The MUC1 cytoplasmic tail interacts with proteins involved in neoplasia and cell adhesion, such as c-Src, Lyn and p120ctn, ${ }^{20-22}$ GSK-3 $\beta,{ }^{23}$ PKC $\delta,{ }^{24}$ and the four members of the ErbB receptor family. These interactions induce signaling pathways such as "mitogen-activated protein kinase" (MAPK). ${ }^{18}$ Therefore, MUC1 governs both cellular differentiation and proliferation. MUC1 is also involved in metastasis because of its role in tumor proliferation ${ }^{25}$ and its antiadhesive activity. ${ }^{26-28}$ This is due to its ability to bind $\beta$-catenin and other family members ( $\gamma$-catenin but not $\alpha$-catenin) ${ }^{24,29}$ which are involved in cell interaction and transcriptional regulation. ${ }^{30}$ A Ser-rich motif (SRM) in the MUC1 cytoplasmic domain is able to bind directly to the $\beta$-catenin armadillo repeat ${ }^{31}$ (Fig. 2). This interaction can be regulated by formation of a MUC1-APC (adenomatosis polyposis coli) complex. APC is a tumor suppressor gene, which downregulates $\beta$-catenin expression. ${ }^{32}$ MUC1 can also activate the phosphoinositide 3-kinase (PI3K)/Akt and Bcl-xl antiapoptotic pathways. ${ }^{33}$ Neuregulin-1 induces the formation of an ErbB2-MUC1 complex and allows MUC1 association with $\gamma$-catenin, inducing its nuclear translocation. Such a complex is only observed in tumor cells, suggesting MUC1 to be a master regulator of the ErbB2 and Wnt pathways. ${ }^{34}$ The MUC1 cytoplasmic tail (MUC1CT) has the ability to shuttle into the nucleus by associating with nucleoporin Nup62 $2^{35}$ and can also interact with transcription factors such as KLF4, p53, ${ }^{36}$ or receptor FGFR $3^{37}$ and therefore alter the biological properties of cells. In breast cancer cells, MUC1CT represses p53-mediated transcription by binding to KLF4 and recruiting histone deacetylase1/3 (HDAC1/3). ${ }^{36}$ FGF1 increases FGFR3-MUC1CT interaction and also induces phosphorylation of MUC1 on the YVEF motif, activating nuclear translocation of MUC1CT and $\beta$-catenin (Fig. 2). ${ }^{37} \mathrm{MUC1}$ expression regulates degradation of ErbB1 by decreasing EGF-stimulated ubiquitination of ErbB1 and by increasing ErbB1 recycling. ${ }^{38}$ Platelet-derived growth factor (PDGF) catalyzes a Tyr phosphorylation site (HGRYVPP) on MUC1CT and enhances invasion in vitro and tumor growth and metastases in vivo. ${ }^{39}$ Recent work has shown that the MUC1 C-terminus ( $\mathrm{Ct}$ ) subunit is glycosylated on Asn-36 and upregulates expression of the lectin galectin-3. In turn, galectin-3 binds to MUC1-Ct at the glycosylated Asn-36 site and forms a bridge between MUC1 and the EGF receptor (Fig. 2). Galectin-3 is essential for EGF-mediated interactions between MUC1 and EGFR. ${ }^{40}$ MUC1 can mediate tumor cell interactions via the ICAM-1 adhesion molecule and its extracellular domain. ${ }^{41}$ This strongly indicates an important role for MUC1 in heterotypic adhesion events, suggesting that MUC1 may promote migration and extravasation of metastatic cells via interaction with endothelial cells.

\section{II.D. The Role of MUC1 in Drug Resistance}

Recent studies have shown that tumor cells expressing MUC1 exhibit an increased capacity to resist the effects of chemotherapeutic drugs. Ren and colleagues ${ }^{42}$ demonstrated that in colorectal cells treated with the genotoxic agent cisplatine, MUC1 attenuated (1) apoptotic mitochondrial factors release, (2) caspase-3 activation, and 


\section{N. JoncKheERE \& I. VAN SEUningen}

(3) apoptosis induction. Moreover, MUC1 inhibition in mammary and lung tumor cells has been found to increase their sensitivity to genotoxic drugs by decreasing the apoptotic effect following DNA structure modifications. MUC1 can also reduce apoptosis following oxidative stress by regulating intracellular levels of reactive oxygen species (ROS).$^{43}$ The antitumoral drug indol-3-carbitol inhibits MUC1 expression in mammary cancer cells at a transcriptional level. ${ }^{44}$ In pancreatic tumor cells, mucin O-glycosylation inhibitor benzyl- $\alpha$-GalNAc promotes the effectiveness of 5-fluorouracil (5-FU). ${ }^{45}$ Thus, intracellular uptake of 5-FU is enhanced in a reduced extracellular matrix environment. ${ }^{46}$

\section{II.E. Muc1 Orthologue}

The mouse homologue $\mathrm{Muc1}$, located on chromosome 3, exhibits strongly conserved TM and cytoplasmic domains compared with those of human Mucl. ${ }^{47}$ The TR contains 16 repeats of 20-21 aa and only shows 34\% homology with human MUC1 and the most significant homology rises to $87 \%$ for the TM domain and cytoplasmic tail. The 5'-flanking regions also share a high homology with the human sequence (74\%). In particular, a region immediately upstream of the TATAA box is highly conserved, displaying close to $100 \%$ identity between human and mouse sequences. Globally, human MUC1 peptide sequences shares $70 \%$ and $72 \%$ homology with mouse and rat Muc1 orthologues, respectively.

Mouse models have provided great insight into the roles of MUC1 in vivo and have provided evidence of a direct role for MUC1 in tumor progression. In studies of a mouse model expressing Muc1 mucin cDNA, it was found that the transfectants expressing human mucin showed a reduction in tumor incidence at low inocula and a delay in tumor growth at higher inocula. ${ }^{48}$ This indicated for the first time that Muc1 participates in tumor progression. Mice deficient in Muc1 mucin appeared to develop normally and were healthy and fertile, and these mice showed a significantly slower growth rate of primary breast tumors. ${ }^{49}$

In conclusion, MUC1, with important structural domains conserved throughout evolution, plays key roles in cell signaling, differentiation, and proliferation of epithelial cells. Biological properties of MUC1, its altered expression, and post-translational modifications in cancers also confer an important role to MUC1 in tumor progression, metastasis, and cancer cell chemoresistance.

\section{MUC4}

\section{III.A. Structure of the MUC4 Gene}

MUC4 was originally identified in our laboratory from a human tracheobronchial mucosa cDNA library using a polyclonal antiserum raised against neutral, sialylated, and sulfated mucin glycoproteins. ${ }^{50,51}$ The $M U C 4$ gene resides on chromosome 3 at 
$\mathrm{q} 29,{ }^{52}$ is $30.8 \mathrm{~kb}$ in size, and contains 26 exons. ${ }^{53-55}$ Exon 1 encodes the $5^{\prime}$-UTR (untranslated) region and the signal peptide, whereas exon 2 contains a long sequence of 951 aa followed by a long TR sequence constituting a central domain. Twenty-four exons of 65 to $607 \mathrm{bp}$ are located in the $3^{\prime}$-end, including an alternate exon only present in the sv1 splice variant. To date, 24 cDNAs transcribed from the MUC4 gene have been identified. These transcripts are the result of a complex alternative splicing mechanism and encode distinct isoforms. Six variants are membrane bound and 18 are secreted. These variants are named sv0 to sv21-MUC4, MUC4/X, and $M U C 4 / Y$. MUC4/X and MUC4/Y represent two membrane-bound variants lacking a mucintype central domain. ${ }^{8}$ The MUC4 complete form sv0-MUC4 is the main isoform expressed in human tissues. For the other forms, sv1-sv24, their expression at the protein level remains to be proven.

Transcript sizes vary from 14 to $26 \mathrm{~kb}$, depending on the VNTR-type polymorphism. ${ }^{55}$ Moreover, intron 3 contains a mini-satellite polymorphism with a 15 -bp motif. Intron 4 contains a 26-32 sequence repeated in tandem, and a 32-bp sequence is repeated in exon $5 .{ }^{56}$

\section{III.B. Structure of the MUC4 Protein}

The MUC4 membrane-bound mucin lacks polymerization domains because its von Willebrand factor D (VWD) domain is unusual in that it lacks cysteines (Fig. 1). MUC4 contains EGF-like domains in its extracellular subunit, which also contains the TR domain..$^{57}$ These EGF domains are conserved in mouse and rat orthologues. ${ }^{58,59}$ The MUC4 N-terminus (Nt)-deduced aa sequence contains a signal peptide and 27 aa followed by three imperfect repeats of a 126-130 aa motif and a unique sequence of 554 aa. These last two domains are Pro/Thr/Serrich (PTS domain). The central domain contains a perfect repeat of 16 aa, which can be repeated between 145 and 395 times. The $\mathrm{Ct}$ region is divided into 12 domains (CT1 to CT12): 2 heavily Nglycosylated domains (Nidogenand AMOP domains), a Cys-rich D domain, 3 EGF domains, a 14 aa TM domain and a short 22-aa cytoplasmic domain. ${ }^{8,60} \mathrm{~A}$ GPDH

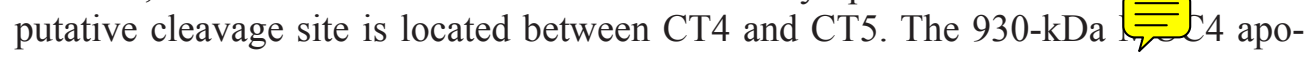
mucin is composed of two subunits: MUC4 $\alpha$ and MUC4 $\beta$. MUC4 is a mucin with a 2.12- $\mu \mathrm{m}$-long membrane-bound extracellular domain. Whereas MUC4 $\alpha$ represents the glycosylated mucin-type subunit, MUC4 $\beta$ represents the growth factor-like membrane-bound subunit (Fig. 1). Experimental evidence suggests that the EGF-like domain plays a role in receptor-ligand interactions. The interaction of the MUC4 EGFlike motif with ErbB2 is the most well characterized, likely serving as a regulator in signaling related to growth, motility, or differentiation properties of the cell. ${ }^{30,61-63} \mathrm{It}$ has been speculated that EGF domains located in released extracellular domains of mucins (resulting from cleavage) could also act as growth factors and serve as indicators of alteration of epithelial surfaces. The functions of the other specific domains comprising MUC4 remain largely unknown. The presence of the AMOP domain in cell adhesion molecules, however, hints toward a role for this domain in adhesion. ${ }^{64}$ 


\section{N. JoncKheERE \& I. VAN SEUningen}

The NIDO nidogen domain is an extracellular domain of unknown function found in nidogen and hypothetical proteins.

\section{III.C. The Role of MUC4 in Carcinogenesis}

Initial in vitro reports indicated that MUC4 might play an important role in the behavior of epithelial tumor cells. Inhibition of MUC4 expression by integration of MUC4 antisense RNA (siRNA) leads to reduced proliferation, motility, and increased cellular aggregation. These cells express a low level of ErbB2 as well as its phosphorylated active form. ${ }^{65}$ Xenografts of cells lacking MUC4 are typically smaller, and metastasis in lymph nodes is reduced. From these studies, it has been hypothesized that MUC4 participates in pancreatic tumor progression by directly altering tumor cell properties, possibly via a modulation of ErbB2 expression (Fig. 3). Nagy and coworkers ${ }^{66}$ showed that MUC4 also plays a role in resistance to the chemotherapeutic drug herceptin. In the herceptin-resistant cell line JIMT-1, ErbB2 is partly masked by MUC4, leading to diminished binding of herceptin to ErbB2, whereas knockdown of MUC4 by RNA interference results in the increased binding of herceptin. Therefore,

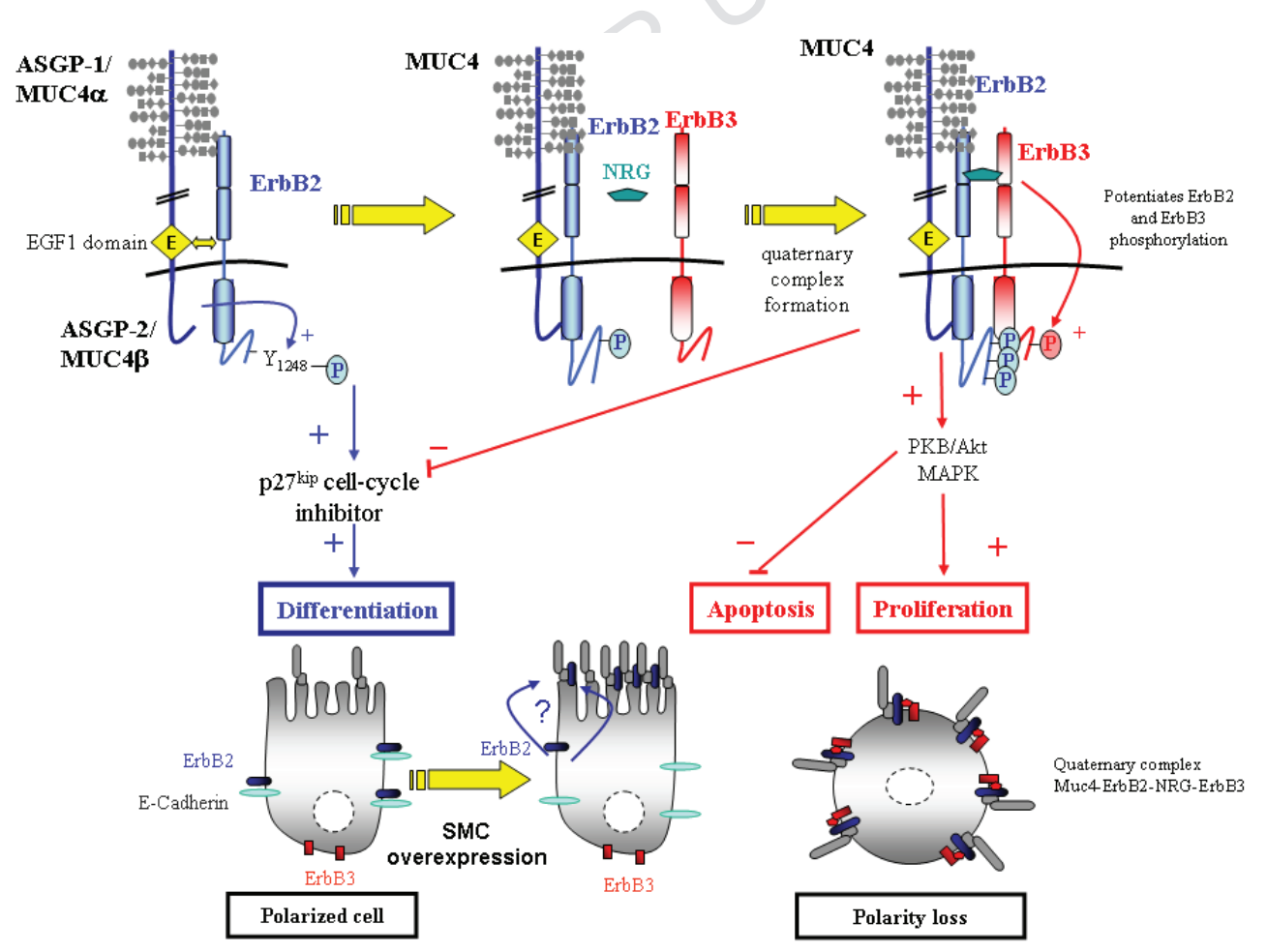

FIGURE 3. MUC4 and cell signaling. MUC4 interacts with ErbB2 and acts as a modulator between proliferation and differentiation via activation of the cell cycle inhibitor p27kip or PKB/ Akt MAPK signaling pathways. 
MUC4 might be of potential use as a prognostic indicator of a tumor sensitivity to herceptin. This is of great interest because cancer cell resistance to herceptin is common, yet its cause remains unclear. ${ }^{66}$

\section{III.D. Muc4 Orthologues}

So far, mouse, rat, and chicken orthologues of Muc4 have been characterized. Mouse Muc4 is localized in the region of chromosome 16, which exhibits synteny with human chromosome 3q29 where human MUC4 is located. mMuc4 contains a total of 25 exons and an identical exon/intron structure to human $M U C 4$. Deduced peptidic sequences indicate that the domain organization has similarities with human MUC4. mMuc4 contains three EGF-like motifs and a mucin-like domain consisting of at least 20 TRs of 124-126 aa. ${ }^{58}$ It is envisaged that a Muc4-knockout mouse model will undoubtedly provide important information as to a direct role of MUC4 in tumorigenesis, especially pancreatic ${ }^{67}$ or esophageal carcinoma. ${ }^{68}$

Rat Muc4, also known as SialoMucin Complex (SMC), has been extensively characterized. Ascites SialoGlycoProtein-1 (ASGP1) is the homologue of mucin-like subunit MUC4 $\alpha$, and ASGP2 is the homologue of the TM subunit MUC4 $\beta$ (Fig. 3). ${ }^{69}$ ASGP1 contains the Ser/Thr-rich domain, and ASGP2 contains two EGF-like domains, a Cys-rich stretch, a TM domain, and a short cytoplasmic tail. SMC exists either as a membrane-bound form or as a soluble form, resulting from proteolytic cleavage. Globally, the MUC4 peptide shares a mild homology with mouse Muc4 $(60 \%)$ and rat SMC (61\%). The chicken homologue of Muc4 is located on chromosome $9 .^{70}$ The predicted protein (ENSEMBL: http://www.ensembl.org) contains all the domains characteristic of human MUC4.

\section{SMC and Cell Signaling}

The biological roles of SMC have been most extensively studied by Carraway and colleagues. ${ }^{30}$ Deciphering the role of SMC in cancer progression was extremely important since most biological functions attributed to MUC4 are based on the structural homology between MUC4 and SMC. SMC has been shown to have intrinsic properties, such as antiadhesive activity involved in cell-cell or cell-matrix interactions, tumor progression, or metastasis. SMC is also able to interact with the oncogenic receptor ErbB2 and modulates its downstream signaling pathway ${ }^{30}$ (Fig. 3).

Initial reports showed that the EGF1 domain of ASGP2 binds to ErbB2 before the two components are released at the cell surface. In A375 cells, SMC overexpression induces Tyr1248 phosphorylation of ErbB2. ${ }^{63}$ Tyr1248 is known to be involved in cell transformation. ${ }^{71}$ Moreover, treatment with the ErbB3 ligand neuregulin, without SMC, induces phosphorylation of both ErbB2 and ErbB3. Combined treatment with neuregulin and SMC overexpression potentiates the phosphorylation of ErbB2 and ErbB3 and induces ErbB2-ErbB3 complex formation (Fig. 3). ErbB2-Tyr1248 phosphorylation by SMC is independent of the adhesion state of cells and does not 


\section{N. JoncKheERE \& I. VAN SEUningen}

activate MAPK, PKB/Akt, or PI3K pathways. However, SMC potentiates the PKB/ Akt pathway following neuregulin treatment, represses apoptosis, and induces proliferation. ${ }^{63} \mathrm{PKB} /$ Akt represses the cell cycle inhibitor p27kip and stimulates cell cycle progression. Altogether, these observations suggest that SMC acts as a differentiation receptor by inducing ErbB2-limited phosphorylation and as a proliferation modulator when SMC acts synergistically with neuregulin and induces phosphorylation of ErbB2 and ErbB3.

In polarized cells of the colon carcinoma cell line Caco-2, ErbB2 is localized at the basolateral side, whereas SMC is located at the apical side. Transient overexpression of SMC leads to ErbB2 translocation to the apical side, where it interacts with SMC and is phosphorylated on Tyr $1248 .{ }^{72}$ Ramsauer et al. ${ }^{72}$ hypothesize that ErbB2 behaves as an $\equiv$ rity sensor of epithelial cells dependent upon SMC-ErbB2 complex formation. Loss of polarity converts the cell from a differentiated state associated with SMC-ErbB2 at the apex to a proliferating state associated with SMCErbB2-ErbB3-neuregulin quaternary complex formation (Fig. 3).

\section{The Role of SMC in Tumor Progression}

SMC overexpression in A375 melanoma cells leads to cell-cell or cell-extracellular matrix interactions disruption in a reversible manner. ${ }^{73}$ The antiadhesion effect is related to SMC expression and SMC protein size, due to its polymorphism. These interaction inhibitions are due to steric hindrance because of their large glycosylated extracellular domains. ASGP1 $(500 \mathrm{~nm})$ could mask cell surface adhesion molecules such as integrin $(30 \mathrm{~nm})$ (Fig. 1). SMC overexpression also blocks access to surface antigens and cytotoxic immune "lymphokine associated killer" (LAK) cells and confers resistance properties to antitumor immunity. Moreover, sialyl Lewis-x located on ASGP1 is an E-selectin ligand..$^{74}$ Therefore, SMC might act as an adhesion molecule in the process of extravasation of a primary tumor toward the blood or lymphatic system (Fig. 4).

Initially, SMC was isolated from a highly aggressive mammary adenocarcinoma. SMC is thought to contribute to tumor invasion and metastasis. Solid mammary tumors express a low level of SMC, whereas SMC is highly expressed in aggressive tumor cells extracted from spleen effusion. SMC overexpression increases the metastatic properties of xenografted A375 cells. This increase is due to a reduction of the cleaved caspase product, leading to the reduction of apoptosis. ${ }^{75}$

\section{SMC and Drug Resistance}

Combined with its proliferative role, SMC plays a role in cancer cell resistance to chemotherapeutic drugs. SMC overexpression reduces the binding of the anti-ErbB2 antibody 4D5 in A375 human melanoma cells and MCF7 breast adenocarcinoma

cells. The expression level of ErbB2 is unaltered, which supports the hypothesis of a steric blockage related to SMC-ErbB2 complex formation. ${ }^{76}$ Trastuzumab/Herceptin ${ }^{\circledR}$ 
The Membrane-Bound Mucins: O-Glycoproteins

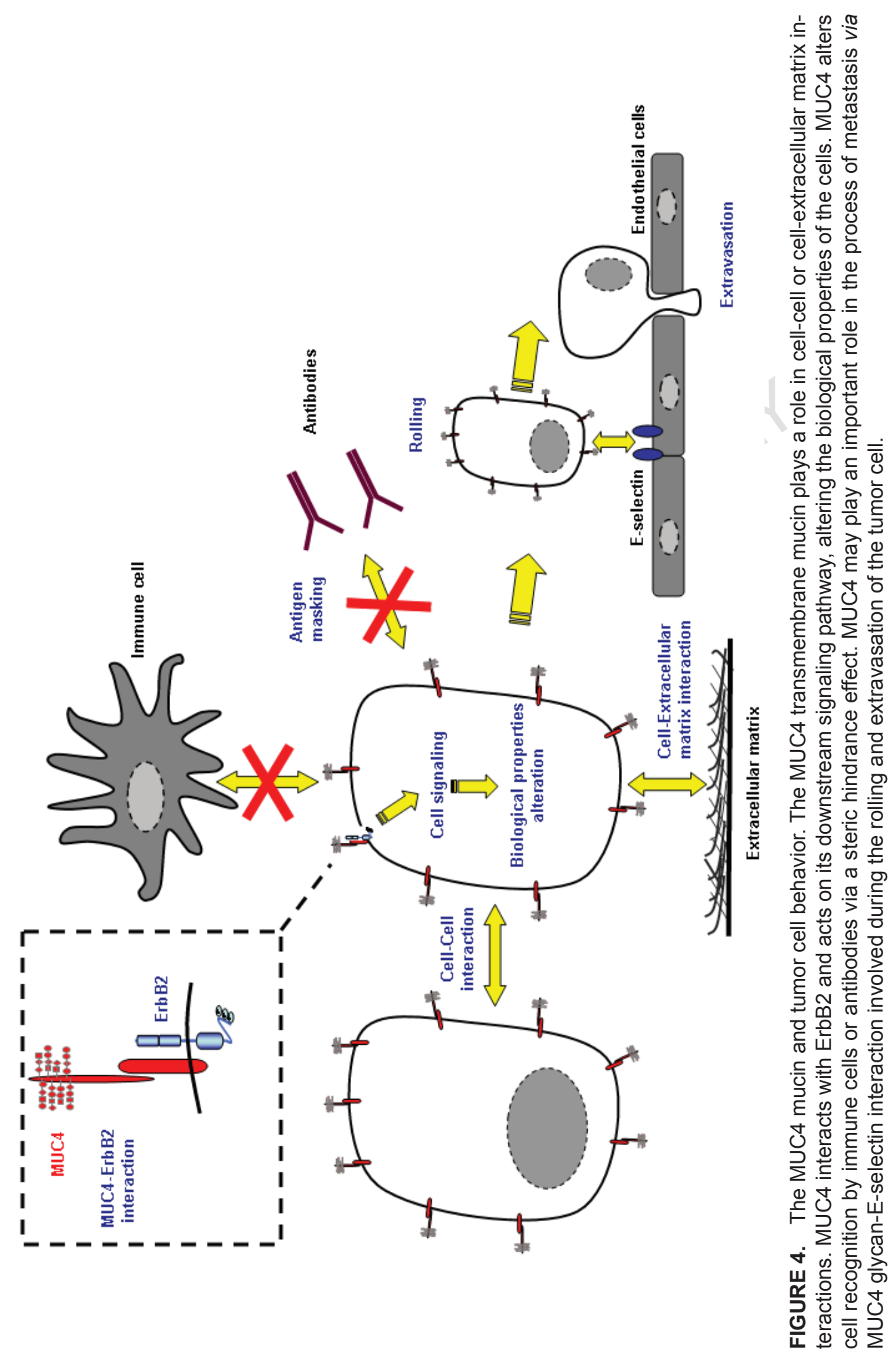




\section{N. JoncKheERE \& I. VAN SEUningen}

is a monoclonal antibody that acts on ErbB2. Overexpression of SMC by the tumor cell might be a resistance mechanism against herceptin and could therefore be of therapeutic value. It was also shown that SMC provides resistance against chemotherapeutic agents such as taxol, doxorubicine, vinblastin, rhodamine-123, and the 2-deoxyglucose glycolytic inhibitor. ${ }^{77}$ However, SMC-expressing cells maintain a strong resistance to these chemotherapeutic drugs, despite a low level of active antitumor drug transporters, such as glycoprotein P "multidrug resistance" (MDR1) and MDR-related protein (MDRP1). The mechanism responsible for the absence of alteration of sensitivity remains unclear. Reduced apoptosis might be a possibility because SMC inhibits caspase-9 expression.

\section{PERSPECTIVES: MUCs AS THERAPEUTIC TOOLS?}

Mucins are thought to play important roles in the biological properties of tumor cells. One could consider mucins as promising therapeutic tools. For this reason, the development of new biological tools targeting mucins for gene therapy and immunotherapeutic approaches has drawn a lot of attention and hope for the future.

\section{IV.A. Immunotherapy}

Aberrant expression of the MUC1 core peptide and its glycosylation on human epithelial cancer cells leads to the targeting of tumor-associated epitopes recognized by specific antibodies and cytotoxic T cells. Consequently, these epitopes could be considered as immunotherapeutic targets. Numerous studies are targeting MUC1 in a wide array of cancer models. The MUC1 peptide core or glycopeptide has been used in immunotherapy for immunization. The different strategies showed T-cell and antibody responses and then were challenged for tumor protection. An elegant summary of these strategies can be found in recent reviews by Tang and Alastolopoulos ${ }^{78}$ and Tang et al. ${ }^{79}$ The role of the microenvironment still needs to be deciphered. Thus, naturally occurring MUC1-specific cytotoxic T-cells (CTLs) were isolated and were thought to be capable of preventing or delaying tumor formation in MUC1.Tg transgenic mice, which develop spontaneous tumors of the pancreas.$^{80}$ However, subsequent study showed that these CTLs were nonfunctional within the pancreatic tumor microenvironment, suggesting the use of several immune-evasion mechanisms by tumor cells to evade destruction by CTLs. Alteration of the tumor microenvironment will be necessary for developing an effective immunotherapeutic strategy. ${ }^{81}$ Immuno- and radiotherapy can be combined to increase efficiency and tumor response. For example, Mab-PAM4 is an anti-MUC1 antibody that reacts with $85 \%$ of pancreatic adenocarcinomas but shows no reactivity against normal pancreas or other tissues. Combined chemotherapy with Gemcitabine and low-dose (131)I-PAM4 radioimmunotherapy may provide an improved alternative for the treatment of pancreatic cancer. ${ }^{82}$ So far, the most advanced clinical trial is a pilot phase III study in early breast cancer using a 
MUC1 fusion protein with oxidized mannan and tamoxifen treatment, which leads to the production of IFN- $\gamma$-secreting T cells. None of the MUC1-injected group showed recurrence, whereas 4 out of 16 recurrences were observed in the placebo group. ${ }^{83}$

Next to MUC1, the main-targeted mucin in immunotherapy, recent assays have targeted other membrane-bound mucins. One study showed that anti-MUC3 IgG antibody was generated after immunization of naïve peripheral blood B lymphocytes, suggesting possible applications in tumor targeting and immunotherapy ${ }^{84}$ Toward the goal of making MUC1 a potential target for immunotherapy, DNA vaccines were also developed. ${ }^{78}$ Plasmids encoding human MUC1 and mouse interleukin-18 (pmuIL-18) were generated, and pMUC1/pmuIL-18 vaccinations protected MUC1 transgenic mice from subcutaneous challenge. ${ }^{85}$ A more recent study showed that pMUC1/ pmuIL-18 is effective in preventing and treating pulmonary metastases in MUC1.Tg mice, breaks tolerance to MUC1, and induces antigen-specific immunity with protective and therapeutic benefit in MUC1 $1^{+}$tumors. ${ }^{86}$ The first studies aimed at using MUC4 in vaccine therapy have been very recently published. A dendritic cell (DC)based vaccine was developed using cells transduced with the universal DR-restricted Th helper epitope (PADRE) combined with human leukocyte antigen (HLA)-A1- and HLA-A2- restricted epitopes from MUC4 (rAd-pE-DCs). Lymphocytes primed with rAd-pE-DCs generated potent cytotoxic responses, suggesting that the PACRE/MUC4 DNA vaccine could be a potential strategy for immunotherapy of $\mathrm{MUC4}^{+}$tumors. ${ }^{87}$

\section{IV.B. Gene-Based Therapy}

Another way to use membrane-bound mucins as therapeutic tools is a gene transfer strategy. In 2004, Aberle and coworkers ${ }^{88}$ monitored the promoter activity of a variety of genes shown to be highly expressed in gastric tumor cells. The MUC1 promoter was among those showing the highest activity, whereas others, such as the MUC4 promoter, were moderately expressed when driving cytokine deaminase. The MUC1 promoter appears to be highly capable of driving a suicide-gene construct in gastric tumors. Further specific studies are required to demonstrate the ability of the $M U C 1$ promoter to target each tumor model. MUC1 and MUC4 exhibit a cell-specific pattern of expression in epithelial cancers. Subsequently, promoters could be used to drive cytotoxic agents. Adenovirus with $M U C 1$ promoter driving human somatostatin receptor subtype 2 (hSSTR2) in Panc-1 pancreatic cells demonstrates a significant inhibition of cell proliferation and could be used as a novel specific tool for genetargeting therapy in $\mathrm{MUC1}^{+}$pancreatic carcinoma. ${ }^{89}$

\section{CONCLUSION}

Membrane-bound mucins are modular proteins that contain conserved domains, such as the epidermal growth factor-like (EGF) domain, potentially involved in important cell signaling pathways. This conserved structure of MUC1 and MUC4 membrane- 


\section{N. JonCKHEERE \& I. VAN SEUNingen}

bound mucins confers them with important biological roles in extracellular cell-cell and cell-matrix interactions, and in cell signaling, especially involving the ErbB oncogenic receptor family. The structure and known functions of mucins to date implicate a role in driving cancer cells toward carcinogenesis. Thus, membrane-bound mucins offer exciting opportunities as potential therapeutic targets in epithelial cancers. Numerous currently running clinical trials in immunotherapy or DNA vaccine targeting MUC1 in a wide array of cancer models are extremely promising.

MUC4-vaccinated dendritic cells showing cytotoxic responses also allow us to propose MUC4 as a promising therapeutic tool. Using MUC4 as a therapeutic tool is of great interest because of its specific pattern of expression, especially in pancreatic cancer where MUC4 expression is induced during carcinogenesis, whereas it is not expressed in normal pancreas. This is extremely hopeful because pancreatic cancer drastically needs new therapeutic approaches to reduce its disastrous survival rate.

Further clinical trials need to be carried out in early cancer patients to determine the efficiency of using membrane-bound mucin-based vaccines. In the future, it is hoped that increased knowledge will lead to an efficient therapeutic cancer vaccine that can be used not only in cancer patients but also in populations at high risk of developing cancer.

\section{ACKNOWLEDGMENTS}

We are grateful to Dr. Philip A. Seymour (University of California at San Diego, USA) for his critical reading of the manuscript. N.J. is the recipient of a postdoctoral fellowship from the Institut National du Cancer (INCa). This work is funded by the Ligue Nationale Contre le Cancer (I.V.S., Equipe Labellisée LIGUE 2008).

\section{REFERENCES}

1. Jonckheere N, Van Seuningen I. The ever growing family of membrane-bound mucins. In: Van Seuningen I, editor. The epithelial mucins: structure/function. Roles in cancer and inflammatory diseases. Kerala (India): Research Signpost; 2008. p. 17-38.

2. Swallow DM, Gendler S, Griffiths B, Corney G, Taylor-Papadimitriou J, Bramwell ME. The human tumour-associated epithelial mucins are coded by an expressed hypervariable gene locus PUM. Nature. 1987;328(6125):82-4.

3. Lan MS, Batra SK, Qi WN, Metzgar RS, Hollingsworth MA. Cloning and sequencing of a human pancreatic tumor mucin cDNA. J Biol Chem. 1990;265(25):15294-9.

4. Ligtenberg MJ, Vos HL, Gennissen AM, Hilkens J. Episialin, a carcinoma-associated mucin, is generated by a polymorphic gene encoding splice variants with alternative amino termini. J Biol Chem. 1990;265(10):5573-8.

5. Lancaster CA, Peat N, Duhig T, Wilson D, Taylor-Papadimitriou J, Gendler SJ. Structure and expression of the human polymorphic epithelial mucin gene: an expressed VNTR unit. Biochem Biophys Res Commun. 1990;173(3):1019-29. 


\section{The Membrane-Bound Mucins: O-Glycoproteins}

6. Fowler JC, Teixeira AS, Vinall LE, Swallow DM. Hypervariability of the membraneassociated mucin and cancer marker MUC1. Hum Genet. 2003;113(6):473-9.

7. Carvalho F, Seruca R, David L, Amorim A, Seixas M, Bennett E, Clausen H, SobrinhoSimoes M. MUC1 gene polymorphism and gastric cancer-an epidemiological study. Glycoconj J. 1997;14(1):107-11.

8. Moniaux N, Escande F, Porchet N, Aubert JP, Batra SK. Structural organization and classification of the human mucin genes. Front Biosci. 2001;6:D1192-206.

9. Gendler SJ, Spicer AP. Epithelial mucin genes. Annu Rev Physiol. 1995;57:607-34.

10. Brayman M, Thathiah A, Carson DD. MUC1: a multifunctional cell surface component of reproductive tissue epithelia. Reprod Biol Endocrinol. 2004;2:4.

11. Levitin F, Stern O, Weiss M, Gil-Henn C, Ziv R, Prokocimer Z, Smorodinsky NI, Rubinstein DB, Wreschner DH. The MUC1 SEA module is a self-cleaving domain. J Biol Chem. 2005;280(39):33374-86.

12. Parry S, Silverman HS, McDermott K, Willis A, Hollingsworth MA, Harris A. Identification of MUC1 proteolytic cleavage sites in vivo. Biochem Biophys Res Commun. 2001;283(3):715-20.

13. Pemberton LF, Rughetti A, Taylor-Papadimitriou J, Gendler SJ. The epithelial mucin MUC1 contains at least two discrete signals specifying membrane localization in cells. J Biol Chem. 1996;271(4):2332-40.

14. Taylor-Papadimitriou J, Burchell J, Miles DW, Dalziel M. MUC1 and cancer. Biochim Biophys Acta. 1999;1455(2-3):301-13.

15. Wreschner DH, Hareuveni M, Tsarfaty I, Smorodinsky N, Horev J, Zaretsky J, Kotkes P, Weiss M, Lathe R, Dion A, Keydar I. Human epithelial tumor antigen cDNA sequences. Differential splicing may generate multiple protein forms. Eur J Biochem. 1990;189(3):463-73.

16. Zrihan-Licht S, Vos HL, Baruch A, Elroy-Stein O, Sagiv D, Keydar I, Hilkens J, Wreschner DH. Characterization and molecular cloning of a novel MUC1 protein, devoid of tandem repeats, expressed in human breast cancer tissue. Eur J Biochem. 1994;224(2):787-95.

17. Zrihan-Licht S, Baruch A, Elroy-Stein O, Keydar I, Wreschner DH. Tyrosine phosphorylation of the MUC1 breast cancer membrane proteins. Cytokine receptor-like molecules. FEBS Lett. 1994;356(1):130-6.

18. Schroeder JA, Thompson MC, Gardner MM, Gendler SJ. Transgenic MUC1 interacts with epidermal growth factor receptor and correlates with mitogen-activated protein kinase activation in the mouse mammary gland. J Biol Chem. 2001;276(16):13057-64.

19. Gendler SJ. MUC1, the renaissance molecule. J Mammary Gland Biol Neoplasia. 2001;6(3):339-53.

20. Li Y, Kufe D. The human DF3/MUC1 carcinoma-associated antigen signals nuclear localization of the catenin p120(ctn). Biochem Biophys Res Commun. 2001;281(2):440-3.

21. Li Y, Chen W, Ren J, Yu WH, Li Q, Yoshida K, Kufe D. DF3/MUC1 signaling in multiple myeloma cells is regulated by interleukin-7. Cancer Biol Ther. 2003;2(2):187-93. 


\section{N. JonckHeERE \& I. VAN Seuningen}

22. Pandey P, Kharbanda S, Kufe D. Association of the DF3/MUC1 breast cancer antigen with Grb2 and the Sos/Ras exchange protein. Cancer Res. 1995;55(18):4000-3.

23. Li Y, Kuwahara H, Ren J, Wen G, Kufe D. The c-Src tyrosine kinase regulates signaling of the human DF3/MUC1 carcinoma-associated antigen with GSK3 beta and betacatenin. J Biol Chem. 2001;276(9):6061-4.

24. Ren J, Li Y, Kufe D. Protein kinase C delta regulates function of the DF3/MUC1 carcinoma antigen in beta-catenin signaling. J Biol Chem. 2002;277(20):17616-22.

25. Ho JJ, Kim YS. Serological pancreatic tumor markers and the MUC1 apomucin. Pancreas. 1994;9(6):674-91.

26. Satoh S, Hinoda Y, Hayashi T, Burdick MD, Imai K, Hollingsworth MA. Enhancement of metastatic properties of pancreatic cancer cells by MUC1 gene encoding an antiadhesion molecule. Int J Cancer. 2000;88(4):507-18.

27. van de Wiel-van Kemenade E, Ligtenberg MJ, de Boer AJ, Buijs F, Vos HL, Melief CJ, Hilkens J, Figdor CG. Episialin (MUC1) inhibits cytotoxic lymphocyte-target cell interaction. J Immunol. 1993;151(2):767-76.

28. Wesseling J, van der Valk SW, Vos HL, Sonnenberg A, Hilkens J. Episialin (MUC1) overexpression inhibits integrin-mediated cell adhesion to extracellular matrix components. J Cell Biol. 1995;129(1):255-65.

29. Yamamoto M, Bharti A, Li Y, Kufe D. Interaction of the DF3/MUC1 breast carcinoma-associated antigen and beta-catenin in cell adhesion. J Biol Chem. 1997;272(19): $12492-4$.

30. Carraway KL, Ramsauer VP, Haq B, Carothers Carraway CA. Cell signaling through membrane mucins. Bioessays. 2003;25(1):66-71.

31. Huang L, Chen D, Liu D, Yin L, Kharbanda S, Kufe D. MUC1 oncoprotein blocks glycogen synthase kinase 3 beta-mediated phosphorylation and degradation of betacatenin. Cancer Res. 2005;65(22):10413-22.

32. Hattrup CL, Fernandez-Rodriguez J, Schroeder JA, Hansson GC, Gendler SJ. MUC1 can interact with adenomatous polyposis coli in breast cancer. Biochem Biophys Res Commun. 2004;316(2):364-9.

33. Raina D, Kharbanda S, Kufe D. The MUC1 oncoprotein activates the anti-apoptotic phosphoinositide 3-kinase/Akt and Bcl-xL pathways in rat 3 Y1 fibroblasts. J Biol Chem. 2004;279(20):20607-12.

34. Li Y, Yu WH, Ren J, Chen W, Huang L, Kharbanda S, Loda M, Kufe D. Heregulin targets gamma-catenin to the nucleolus by a mechanism dependent on the DF3/MUC1 oncoprotein. Mol Cancer Res. 2003;1(10):765-75.

35. Leng Y, Cao C, Ren J, Huang L, Chen D, Ito M, Kufe D. Nuclear import of the MUC1-C oncoprotein is mediated by nucleoporin Nup62. J Biol Chem. 2007;282(27):19321-30.

36. Wei X, Xu H, Kufe D. Human mucin 1 oncoprotein represses transcription of the p53 tumor suppressor gene. Cancer Res. 2007;67(4):1853-8.

37. Ren J, Raina D, Chen W, Li G, Huang L, Kufe D. MUC1 oncoprotein functions in activation of fibroblast growth factor receptor signaling. Mol Cancer Res. 2006;4(11):873-83. 


\section{The Membrane-Bound Mucins: O-Glycoproteins}

38. Pochampalli MR, el Bejjani RM, Schroeder JA. MUC1 is a novel regulator of ErbB1 receptor trafficking. Oncogene. 2007;26(12):1693-701.

39. Singh PK, Wen Y, Swanson BJ, Shanmugam K, Kazlauskas A, Cerny RL, Gendler SJ, Hollingsworth MA. Platelet-derived growth factor receptor beta-mediated phosphorylation of MUC1 enhances invasiveness in pancreatic adenocarcinoma cells. Cancer Res. 2007;67(11):5201-10.

40. Ramasamy S, Duraisamy S, Barbashov S, Kawano T, Kharbanda S, Kufe D. The MUC1 and galectin-3 oncoproteins function in a microRNA-dependent regulatory loop. Mol Cell. 2007;27(6):992-1004.

41. Rahn JJ, Shen Q, Mah BK, Hugh JC. MUC1 initiates a calcium signal after ligation by intercellular adhesion molecule-1. J Biol Chem. 2004;279(28):29386-90.

42. Ren J, Agata N, Chen D, Li Y, Yu WH, Huang L, Raina D, Chen W, Kharbanda S, Kufe D. Human MUC1 carcinoma-associated protein confers resistance to genotoxic anticancer agents. Cancer Cell. 2004;5(2):163-75.

43. Yin L, Li Y, Ren J, Kuwahara H, Kufe D. Human MUC1 carcinoma antigen regulates intracellular oxidant levels and the apoptotic response to oxidative stress. J Biol Chem. 2003;278(37):35458-64.

44. Lee IJ, Han F, Baek J, Hisatsune A, Kim KC. Inhibition of MUC1 expression by indole3-carbinol. Int J Cancer. 2004;109(6):810-6.

45. Kalra AV, Campbell RB. Mucin impedes cytotoxic effect of 5-FU against growth of human pancreatic cancer cells: overcoming cellular barriers for therapeutic gain. $\mathrm{Br} \mathrm{J}$ Cancer. 2007;97(7):910-8.

46. Kalra AV, Campbell RB. Mucin overexpression limits the effectiveness of 5-FU by reducing intracellular drug uptake and antineoplastic drug effects in pancreatic tumours. Eur J Cancer. 2009;45(1):164-73.

47. Spicer AP, Parry G, Patton S, Gendler SJ. Molecular cloning and analysis of the mouse homologue of the tumor-associated mucin, MUC1, reveals conservation of potential O-glycosylation sites, transmembrane, and cytoplasmic domains and a loss of minisatellite-like polymorphism. J Biol Chem. 1991;266(23):15099-109.

48. Lalani EN, Berdichevsky F, Boshell M, Shearer M, Wilson D, Stauss H, Gendler SJ, Taylor-Papadimitriou J. Expression of the gene coding for a human mucin in mouse mammary tumor cells can affect their tumorigenicity. J Biol Chem. 1991;266(23):15420-6.

49. Spicer AP, Duhig T, Chilton BS, Gendler SJ. Analysis of mammalian MUC1 genes reveals potential functionally important domains. Mamm Genome. 1995;6(12):885-8.

50. Crepin M, Porchet N, Aubert JP, Degand P. Diversity of the peptide moiety of human airway mucins. Biorheology. 1990;27(3-4):471-84.

51. Porchet N, Nguyen VC, Dufosse J, Audie JP, Guyonnet-Duperat V, Gross MS, Denis C, Degand P, Bernheim A, Aubert JP. Molecular cloning and chromosomal localization of a novel human tracheo-bronchial mucin cDNA containing tandemly repeated sequences of 48 base pairs. Biochem Biophys Res Commun. 1991;175(2):414-22.

52. Gross MS, Guyonnet-Duperat V, Porchet N, Bernheim A, Aubert JP, Nguyen VC. Mucin 4 (MUC4) gene: regional assignment (3q29) and RFLP analysis. Ann Genet. 1992;35(1):21-6. 


\section{N. JoncKheERE \& I. VAN Seuningen}

53. Escande F, Lemaitre L, Moniaux N, Batra SK, Aubert JP, Buisine MP. Genomic organization of MUC4 mucin gene. Towards the characterization of splice variants. Eur J Biochem. 2002;269(15):3637-44.

54. Moniaux N, Nollet S, Porchet N, Degand P, Laine A, Aubert JP. Complete sequence of the human mucin MUC4: a putative cell membrane-associated mucin. Biochem J. 1999;338(Pt 2):325-33.

55. Nollet S, Moniaux N, Maury J, Petitprez D, Degand P, Laine A, Porchet N, Aubert JP. Human mucin gene MUC4: organization of its 5'-region and polymorphism of its central tandem repeat array. Biochem J. 1998;332(Pt 3):739-48.

56. Fowler J, Vinall L, Swallow D. Polymorphism of the human muc genes. Front Biosci. 2001;6:D1207-15.

57. Hollingsworth MA, Swanson BJ. Mucins in cancer: protection and control of the cell surface. Nat Rev Cancer. 2004;4(1):45-60.

58. Desseyn JL, Clavereau I, Laine A. Cloning, chromosomal localization and characterization of the murine mucin gene orthologous to human MUC4. Eur J Biochem. 2002;269(13):3150-9.

59. Carraway KL, Price-Schiavi SA, Komatsu M, Idris N, Perez A, Li P, Jepson S, Zhu $\mathrm{X}$, Carvajal ME, Carraway CA. Multiple facets of sialomucin complex/MUC4, a membrane mucin and erbb2 ligand, in tumors and tissues (Y2K update). Front Biosci. 2000;5:D95-107.

60. Dekker J, Rossen JW, Buller HA, Einerhand AW. The MUC family: an obituary. Trends Biochem Sci. 2002;27(3):126-31.

61. Carraway CA, Carraway KL. Sequestration and segregation of receptor kinases in epithelial cells: implications for ErbB2 oncogenesis. Sci STKE. 2007;2007(381):re3.

62. Carraway KL III, Funes M, Workman HC, Sweeney C. Contribution of membrane mucins to tumor progression through modulation of cellular growth signaling pathways. Curr Top Dev Biol. 2007;78:1-22.

63. Jepson S, Komatsu M, Haq B, Arango ME, Huang D, Carraway CA, Carraway KL. Muc4/ sialomucin complex, the intramembrane ErbB2 ligand, induces specific phosphorylation of ErbB2 and enhances expression of p27(kip), but does not activate mitogen-activated kinase or protein kinaseB/Akt pathways. Oncogene. 2002;21(49):7524-32.

64. Ciccarelli FD, Doerks T, Bork P. AMOP, a protein module alternatively spliced in cancer cells. Trends Biochem Sci. 2002;27(3):113-5.

65. Singh AP, Moniaux N, Chauhan SC, Meza JL, Batra SK. Inhibition of MUC4 expression suppresses pancreatic tumor cell growth and metastasis. Cancer Res. 2004;64(2): 622-30.

66. Nagy P, Friedlander E, Tanner M, Kapanen AI, Carraway KL, Isola J, Jovin TM. Decreased accessibility and lack of activation of ErbB2 in JIMT-1, a herceptin-resistant, MUC4-expressing breast cancer cell line. Cancer Res. 2005;65(2):473-82.

67. Van Seuningen I, Leteurtre E, Pigny P. Mucins in pancreas and hepato-biliary tract. Expression, regulation, biomarkers and therapy. In: Van Seuningen I, editor. The epithelial mucins: structure/function. Roles in cancer and inflammatory diseases. Kerala (India): Research Signpost; 2008. p. 233-48. 


\section{The Membrane-Bound Mucins: O-Glycoproteins}

68. Piessen G, Mariette C, Van Seuningen I. Mucin expression and regulation in oesophageal cancer: new molecular targets in cancer progression from Barrett's oesophagus to adenocarcinoma? In: Van Seuningen I, editor. The epithelial mucins: structure/function. Roles in cancer and inflammatory diseases. Kerala (India): Research Signpost; 2008. p. $169-82$.

69. Wu K, Fregien N, Carraway KL. Molecular cloning and sequencing of the mucin subunit of a heterodimeric, bifunctional cell surface glycoprotein complex of ascites rat mammary adenocarcinoma cells. J Biol Chem. 1994;269(16):11950-5.

70. Lang T, Hansson GC, Samuelsson T. An inventory of mucin genes in the chicken genome shows that the mucin domain of Muc13 is encoded by multiple exons and that ovomucin is part of a locus of related gel-forming mucins. BMC Genomics. 2006;7:197.

71. Ben-Levy R, Paterson HF, Marshall CJ, Yarden Y. A single autophosphorylation site confers oncogenicity to the Neu/ErbB-2 receptor and enables coupling to the MAP kinase pathway. EMBO J. 1994;13(14):3302-11.

72. Ramsauer VP, Carraway CA, Salas PJ, Carraway KL. Muc4/sialomucin complex, the intramembrane ErbB2 ligand, translocates ErbB2 to the apical surface in polarized epithelial cells. J Biol Chem. 2003;278(32):30142-7.

73. Komatsu M, Carraway CA, Fregien NL, Carraway KL. Reversible disruption of cellmatrix and cell-cell interactions by overexpression of sialomucin complex. J Biol Chem. 1997;272(52):33245-54.

74. Jacob GS, Kirmaier C, Abbas SZ, Howard SC, Steininger CN, Welply JK, Scudder P. Binding of sialyl Lewis $\mathrm{x}$ to E-selectin as measured by fluorescence polarization. Biochemistry. 1995;34(4):1210-7.

75. Komatsu M, Jepson S, Arango ME, Carothers Carraway CA, Carraway KL. Muc4/sialomucin complex, an intramembrane modulator of ErbB2/HER2/Neu, potentiates primary tumor growth and suppresses apoptosis in a xenotransplanted tumor. Oncogene. 2001;20(4):461-70.

76. Price-Schiavi SA, Jepson S, Li P, Arango M, Rudland PS, Yee L, Carraway KL. Rat Muc4 (sialomucin complex) reduces binding of anti-ErbB2 antibodies to tumor cell surfaces, a potential mechanism for herceptin resistance. Int J Cancer. 2002;99(6):783-91.

77. Hu YP, Haq B, Carraway KL, Savaraj N, Lampidis TJ. Multidrug resistance correlates with overexpression of Muc4 but inversely with P-glycoprotein and multidrug resistance related protein in transfected human melanoma cells. Biochem Pharmacol. 2003;65(9):1419-25.

78. Tang CK, Apostolopoulos V. Strategies used for MUC1 immunotherapy: preclinical studies. Expert Rev Vaccines. 2008;7(7):951-62.

79. Tang CK, Katsara M, Apostolopoulos V. Strategies used for MUC1 immunotherapy: human clinical studies. Expert Rev Vaccines. 2008;7(7):963-75.

80. Mukherjee P, Ginardi AR, Tinder TL, Sterner CJ, Gendler SJ. MUC1-specific cytotoxic $\mathrm{T}$ lymphocytes eradicate tumors when adoptively transferred in vivo. Clin Cancer Res. 2001;7(3 Suppl):848s-55s.

81. Mukherjee P, Ginardi AR, Madsen CS, Tinder TL, Jacobs F, Parker J, Agrawal B, Lon- 


\section{N. JoncKheERE \& I. VAN SEUningen}

genecker BM, Gendler SJ. MUC1-specific CTLs are non-functional within a pancreatic tumor microenvironment. Glycoconj J. 2001;18(11-12):931-42.

82. Cardillo TM, Blumenthal R, Ying Z, Gold DV. Combined gemcitabine and radioimmunotherapy for the treatment of pancreatic cancer. Int J Cancer. 2002;97(3):386-92.

83. Apostolopoulos V, Pietersz GA, Tsibanis A, Tsikkinis A, Drakaki H, Loveland BE, Piddlesden SJ, Plebanski M, Pouniotis DS, Alexis MN, McKenzie IF, Vassilaros S. Pilot phase III immunotherapy study in early-stage breast cancer patients using oxidized mannan-MUC1 [ISRCTN71711835]. Breast Cancer Res. 2006;8(3):R27.

84. Baritaki S, Zafiropoulos A, Georgopoulos E, Souris S, Krambovitis E. Generation of human anti-MUC3 IgG antibodies after in vitro immunization of naive peripheral blood B-lymphocytes. Cancer Immunol Immunother. 2001;50(2):109-14.

85. Snyder LA, Goletz TJ, Gunn GR, Shi FF, Harris MC, Cochlin K, McCauley C, McCarthy SG, Branigan PJ, Knight DM. A MUC1/IL-18 DNA vaccine induces anti-tumor immunity and increased survival in MUC1 transgenic mice. Vaccine. 2006;24(16):3340-52.

86. Shi FF, Gunn GR, Snyder LA, Goletz TJ. Intradermal vaccination of MUC1 transgenic mice with MUC1/IL-18 plasmid DNA suppresses experimental pulmonary metastases. Vaccine. 2007;25(17):3338-46.

87. Wei J, Gao W, Wu J, Meng K, Zhang J, Chen J, Miao Y. Dendritic cells expressing a combined PADRE/MUC4-derived polyepitope DNA vaccine induce multiple cytotoxic T-cell responses. Cancer Biother Radiopharm. 2008;23(1):121-8.

88. Aberle S, Schug N, Mathlouthi R, Seitz G, Kupper JH, Schroder K, Blin N. Promoter selection for the cytosine deaminase suicide gene constructs in gastric cancer. Eur J Gastroenterol Hepatol. 2004;16(1):63-7.

89. Chen L, Liu Q, Qin R, Le H, Xia R, Li W, Kumar M. Amplification and functional characterization of MUC1 promoter and gene-virotherapy via a targeting adenoviral vector expressing hSSTR2 gene in MUC1-positive Panc-1 pancreatic cancer cells in vitro. Int J Mol Med. 2005;15(4):617-26. 